\title{
Worldwide alteration of lake mixing regimes in response to climate change
}

Article

Accepted Version

Woolway, R. I. ORCID: https://orcid.org/0000-0003-0498-7968 and Merchant, C. J. (2019) Worldwide alteration of lake mixing regimes in response to climate change. Nature Geoscience, 12. pp. 271-276. ISSN 1782-0908 doi:

https://doi.org/10.1038/s41561-019-0322-x Available at https://centaur.reading.ac.uk/82814/

It is advisable to refer to the publisher's version if you intend to cite from the work. See Guidance on citing.

To link to this article DOI: http://dx.doi.org/10.1038/s41561-019-0322-x

Publisher: Nature

All outputs in CentAUR are protected by Intellectual Property Rights law, including copyright law. Copyright and IPR is retained by the creators or other copyright holders. Terms and conditions for use of this material are defined in the End User Agreement.

\section{www.reading.ac.uk/centaur}

\section{CentAUR}

Central Archive at the University of Reading 
Reading's research outputs online 
Worldwide alteration of lake mixing regimes in response to climate change

Author information

R. Iestyn Woolway $^{1 *}$, Christopher J. Merchant ${ }^{1,2}$

1. Department of Meteorology, University of Reading, Reading, UK

2. National Centre for Earth Observation, University of Reading, Reading, UK

*now at Dundalk Institute of Technology, Dundalk, Ireland

Lakes hold much of Earth's accessible liquid freshwater, support biodiversity and provide key ecosystem services to people around the world. However, they are vulnerable to climate change, for example through shorter durations of ice cover, or through rising lake surface temperatures. Here we use a one-dimensional, numerical lake model to assess climate change impacts on mixing regimes in 635 lakes worldwide. We run the lake model with input data from four state-of-the-art model projections of $21^{\text {st }}$ century climate under two emissions scenarios. Under the scenario with higher emissions (Representative Concentration Pathway 6.0), many lakes are projected to have reduced ice cover; about a quarter of seasonally ice-covered lakes are permanently ice-free by 2080-2100. Surface waters are projected to warm, with a median warming across lakes of about $2.5^{\circ} \mathrm{C}$, and the most extreme warming at about $5.5^{\circ} \mathrm{C}$. The projections suggest that around 100 of the studied lakes are projected to undergo changes in their mixing regimes. About a quarter of these lakes which are currently classified as monomictic - that undergo one mixing event in most years - will become permanently stratified systems. About a sixth of these which are currently dimictic that mix twice per year - will become monomictic. We conclude that many lakes will mix less frequently in response to climate change.

Documented climate-related changes in lakes include shorter durations of winter ice cover $^{1-4}$ and higher lake surface temperatures ${ }^{5-9}$. Recent global studies of lake surface temperature trends show that many lakes, predominantly those that experience seasonal ice cover, are warming at rates in excess of ambient air temperature ${ }^{7-8}$. Studies of lake temperature responses to climate change have improved our understanding of the consequences of warming on lake ecosystems ${ }^{10,11}$. Here, we assess for 635 globally distributed large lakes how projected climate trends are likely to change lake stratification and mixing. Because these aspects of lake dynamics exert significant control on nutrient fluxes, oxygenation and biogeochemical cycling ${ }^{12,13}$, considering stratification and mixing is critical for anticipating the repercussions of temperature change throughout lake environments and associated ecosystems.

Stratification and mixing regimes in lakes

Thermal stratification occurs in lakes as a result of the thermal-expansion properties of water. The time evolution of stratification is determined by the balance between turbulence, which acts to enhance mixing, and buoyancy forces, which act to suppress turbulence and result in a 
vertical layering ${ }^{14}$. The vertical layering that exists during stratification exerts strong control on the transport of nutrients and oxygen between the surface and deep water of lakes and the vertical distribution and composition of lake biota. Lakes that are permanently mixed (continuous cold/warm polymictic) or those that mix frequently (discontinuous cold/warm polymictic) differ markedly in their physical, chemical and biological functioning from lakes that are stratified permanently (meromictic) or semi-permanently (oligomictic, characterised by variable temporal periods of incomplete mixing, interspersed with occasional mixing $)^{14,15}$. Lakes that stratify seasonally can be classed as dimictic if they have two stratification seasons, or monomictic (cold or warm) if they stratify only once per year (see Methods; Fig. $\mathrm{S} 1)$. Seasonal mixing serves as a basis for lake regime classification ${ }^{16}$ and as a necessary component of projecting how lake ecosystems will respond to climate change.

The mixing class to which a lake belongs depends primarily on (i) whether or not it experiences ice cover annually, and (ii) the number of times during a year in which it stratifies continuously (Fig. S1). Ice-covered lakes tend to occur in less-maritime, highlatitude and high-elevation regions (Fig. 1A). Satellite observations of 635 lakes from 1995 to 2011 (Table S1), $50 \%$ of which experienced ice cover annually, illustrate that the climatological duration of ice cover varies systematically with mean air temperature (Fig. 1B; produced using air temperature from the ERA-Interim reanalysis ${ }^{17}$ ). With regards to the stratification criterion for mixing class, surface water temperature observations can be used to distinguish between dimictic and monomictic (cold or warm) lakes (Fig. 1C, 1D): in warm monomictic lakes, surface water temperature does not cool below $4^{\circ} \mathrm{C}$ (near the maximum density of freshwater), while in cold monomictic lakes, surface water temperature does not warm above $4^{\circ} \mathrm{C}$. No lake surface water temperature threshold separates thermally stratifying and polymictic lakes, as other factors can have a substantial influence, notably lake depth (e.g., shallow lakes can mix easily). The global heterogeneity of lake sizes and depths ${ }^{18,19}$ suggests that lake-mixing classes should be heterogeneously distributed.

\section{Global patterns of lake mixing regimes}

In this study, we assess the contemporary mixing class of 635 lakes worldwide, by developing a classification scheme applied to numerical simulation results from a lake model, and then use this model to project future mixing classes under climate change scenarios. This approach enables meromictic, oligomictic, monomictic, dimictic and polymictic mixing classes to be determined.

To assess the contemporary mixing classes, we first optimise key parameters of the lake model, FLake ${ }^{20,21}$, to represent the dynamics of each individual lake. The optimisation constrains the model to represent observed lake surface water temperature time series (see Methods). The ability of the optimised lake model to represent a wide range of lake dynamics is evaluated by comparing simulations with independent temperature observations, ice cover and lake mixing regimes under historic climate conditions. Good agreement is obtained (Fig. S2-S7). Particularly relevant to multi-decadal projection is that the lake model is able to simulate accurately historic multi-decadal variations in lake temperature back to the start of the $20^{\text {th }}$ century (Fig. S4) and to identify successfully the mixing regime of $72 \%$ of lakes for which independent mixing regime classifications were found (Fig. S7; Table S2). Up to $85 \%$ 
of inter-decadal variability in lake surface temperature is explained by the lake model forced with representations of historic climate conditions.

The identified lake mixing regimes demonstrate a diverse array of mixing types (Fig. 1E-1F). Dimictic lakes are most common in our global dataset (Fig. S8), a result of the majority of our study lakes being relatively large (all studies lakes exceed $27 \mathrm{~km}^{2}$ in area) and situated north of $40^{\circ} \mathrm{N}$, where the global lake abundance is highest ${ }^{18}$. The proportion of dimictic and polymictic lakes is large in north temperate latitudes, as expected, and meromictic lakes are common in the tropics (Fig. 1E-1F).

\section{Climate-related changes in lake mixing regimes}

To project future changes in mixing class, the lake model is forced by four climate projections available from the Inter-Sectoral Impact Model Intercomparison Project ${ }^{22}$, namely, HadGEM2-ES, GFDL-ESM2M, IPSL-CM5A-LR and MIROC5 (see Methods for details), under two Representative Concentration Pathway (RCP) scenarios. The main figures presented here show the results from the lake model forced with bias-corrected HadGEM2ES projections. To indicate the uncertainty of projections, we show or quote the spread of results from the lake model across all four climate model projections. Changes projected for 2080-2100 are quoted relative to the period 1985-2005.

The responses of lake mixing regimes to climate change are complex and may not be associated closely with change in any one climatic variable. Rather, the mixing regime of a lake will depend on changes in a combination of climatic factors that contribute to the lake heat budget (e.g., air temperature, solar and thermal radiation, cloud cover, wind speed, humidity). Under future scenarios RCP 2.6 and 6.0, we project that the number of annual icecovered days will decrease substantially (Fig. 2A, 2B) by 2080-2100. For RCP 2.6, the decrease is on average (across all lakes that are seasonally ice covered during the historic period) 15 days, the standard deviation of this mean change across the four-member ensemble being 5 days. For RCP 6.0, the projected mean change is $-29 \pm 8$ days. In the most extreme cases under RCP 6.0, the projected decreases of ice-covered days exceed 60 days. The simulations project that $24 \pm 5 \%$ of lakes that display winter ice cover in the historic period will be ice-free by the end of the $21^{\text {st }}$ century under the RCP 6.0 scenario. The increase in annual mean lake surface temperature is projected to be $1.1 \pm 0.4^{\circ} \mathrm{C}$ and $2.3 \pm 0.6^{\circ} \mathrm{C}$ under RCP 2.0 and 6.0, respectively (Fig. 2C, 2D), by 2080-2100. For individual lakes, projected warming can be higher, the largest projected increase being $5.4 \pm 1.1^{\circ} \mathrm{C}$ under RCP 6.0. $99 \pm 0.5 \%$ of lakes are projected to increase in mean temperature under RCP 2.6, and all $(100 \pm 0 \%)$ increase under RCP 6.0 .

Decreases in winter ice cover and increases in lake surface temperatures would be expected qualitatively to modify the distribution of lake mixing regimes. Next, we investigate the global extent and magnitude of response in the projections to quantify this expectation. The projections suggest that alterations in lake mixing regimes will occur during the $21^{\text {st }}$ century (Fig. 3, Fig. S9-S10). Specifically, in the projections under RCP 2.6 and 6.0, respectively, $59 \pm 7$ and $96 \pm 15$ lakes change mixing class. 
The most common identified alteration in mixing class $(25 \pm 5 \%$ of altered lakes under RCP 6.0) is a change from warm monomictic to meromictic. This means that a significant minority of lakes that do not currently experience ice cover and stratify once annually are projected to become permanently stratified systems by the end of the $21^{\text {st }}$ century. In addition, all of the lakes identified as being oligomictic during the historic period transition to the meromictic class by 2080-2100. A lack of vertical mixing by the end of the $21^{\text {st }}$ century will result in reduced upwelling of nutrients from deep to shallow waters and a decrease in deepwater oxygen concentrations, which can lead to reduced lake productivity ${ }^{10}$ and the formation of deep-water dead zones ${ }^{12}$, respectively. Oxygen depletion at depth can be detrimental to the habitat for fish ${ }^{23}$ and can modify biogeochemical processes resulting in, for example, the potential release of phosphorus and ammonium into the water column ${ }^{24}$ and the production of potentially toxic metal ions ${ }^{25}$.

The second most common identified alteration in mixing class (across the model ensemble) is a change from dimictic to warm monomictic ( $17 \pm 5 \%$ of altered lakes under RCP 6.0) (Fig. 3, Fig. S9-S10). This alteration occurs when lakes that were historically ice covered no longer freeze in winter but still stratify during summer. The projected absence of winter ice has implications for those lake ecosystems including, among other things, changes in water quality ${ }^{26}$ and the production and biodiversity of phytoplankton ${ }^{27}$.

A very small number of altered lakes are projected to experience fewer continuous periods of stratification, and, as a result, to transition from being categorized as dimictic to polymictic. Such an increase in mixing can be a result of changes in any of the meteorological drivers acting at the lake surface. Short-term variations in surface wind speed, for example, can play an important role in lake stratification and mixing, and could nudge some lakes to a different mixing regime ${ }^{28}$. The influence of changes in wind speed will, however, be expected to have the most pronounced effects on the mixing regime of shallow lakes. All the lakes that are projected to undergo an increase in the number of mixing events per year are among the shallowest $1 \%$ of the lakes studied. Other factors that were not considered in this study may also be important for mixing regime alterations in specific lakes, such as groundwater inputs ${ }^{29}$, increased inflow of cold water from retreating glaciers ${ }^{30}$, thermal pollution from nuclear plants ${ }^{31}$, and changes in the magnitude of influent water ${ }^{32}$, which will be particularly important for lakes with short residence times or extensive lake level variations ${ }^{33}$. Changes in lake transparency can also influence the mixing regime of lakes ${ }^{34}$, but it is not expected to be a dominant driver of mixing regime alterations in large lakes, such as those included in this study. The influence of transparency on lake mixing and stratification has been shown to decrease with increasing lake size ${ }^{35,36}$ and the vertical thermal structure will be constrained strongly by fetch ${ }^{37}$. Thus, transparency is expected to have a greater influence on the vertical thermal structure of relatively small lakes compared to larger ones, as investigated in this study.

There is scattered evidence of mixing regime alterations already taking place, and ecological consequences of these changes are starting to appear ${ }^{38,39}$. Our projections of future lake-mixing regime alterations span a wide range of locations, sizes, and climatic contexts, and suggest a complex pattern of lake responses to climate change. The geographical 
distribution of lake mixing regime alterations is heterogeneous, because climatic conditions interact with lake-specific contexts, particularly geomorphology. The projections do not support simple expectations of regional consistency in lake responses whereby lakes in a given region will change similarly. Changes in lake temperature will not always translate to changes in lake mixing regimes: some of the lakes which are projected to experience the highest surface warming are not projected to undergo a change in their mixing class. Most lakes that are projected to alter in their mixing regimes currently display anomalous mixing behaviour relative to their dominant mixing classification in some years. Specifically, twothirds of lakes that are projected to experience an alteration in their mixing regimes had at least three years of anomalous mixing regime during the period 1985 to 2005 . Lakes that are currently classified as warm monomictic but fail to mix fully during some winters presently account for $60 \%$ of those that are projected to become meromictic (i.e., permanently stratified) in the future. Lakes that are currently seasonally ice-covered and are classified as dimictic but also experience some ice-free winters are projected to become predominantly monomictic by the end of the $21^{\text {st }}$ century. Thus, the projections confirm the intuition that those lakes that currently exhibit anomalous years relative to their usual mixing class are more likely to transition to a different mixing regime in the future.

\section{References}

1. Sharma, S., et al. Widespread loss of lake ice around the Northern Hemisphere in a warming world, Nature Climate Change (In press).

2. Magnuson, J. J. et al. Historical trends in lake and river ice cover in the Northern Hemisphere. Science 289, 1743-1746 (2000).

3. Fang, X., \& Stefan, H. G. Simulations of climate effects on water temperature, dissolved oxygen, and ice and snow covers in lakes of the contiguous U. S. under past and future climate scenarios. Limnol. Oceanogr. 54, 2359-2370 (2009).

4. Magee, M. R., Wu, C. H., Robertson, D. M., Lathrop, R. C. \& Hamilton, D. P. Trends and abrupt changes in 104 years of ice cover and water temperature in a dimictic lake in response to air temperature, wind speed, and water clarity drivers. Hydrol. Earth Syst. Sci. 20, 1681-1702 (2016)

5. Schneider, P., Hook, S. J. Space observations of inland water bodies show rapid surface warming since 1985, Geophys. Res. Lett. 37, doi:10.1029/2010GL045059

6. Magee, M. R. \& Wu, C. H. Response of water temperatures and stratification to changing climate in three lakes with different morphometry. Hydrol. Earth Syst. Sci. 21, 62536274 (2017).

7. O'Reilly, C. et al. Rapid and highly variable warming of lake surface waters around the globe. Geophys. Res. Lett. 42, 10773-10781 (2015).

8. Austin, J. A., S. M. Colman. Lake Superior summer water temperatures are increasing more rapidly than regional temperatures: A positive ice-albedo feedback. Geophys. Res. Lett. 34, doi:10.1029/2006GL029021. (2007).

9. Livingstone, D. M. Impact of secular climate change on the thermal structure of a large temperate central European lake. Clim. Change 57, 205-225 (2003).

10. O'Reilly, C. et al. Climate change decreases aquatic ecosystem productivity of Lake Tanganyika, Africa. Nature 424, 766-768 (2003).

11. O'Beirne, M. D. et al. Anthropogenic climate change has altered primary productivity in Lake Superior. Nat. Commun. 8, 15713 (2017). 
12. North, R. P. et al. Long-term changes in hypoxia and soluble reactive phosphorus in the hypolimnion of a large temperate lake: consequences of a climate regime shift. Glob. Change Biol. 20, 811-823 (2014).

13. Yankova, Y., Neuenschwander, S., Köster, O. \& Posch, T. Abrupt stop of deep water turnover with lake warming: Drastic consequences for algal primary producers. Sci. Rep. 7, 13770 (2017).

14. Boehrer, B. \& Schultze, M. Stratification of lakes. Rev. Geophys. 46, RG2005 (2008).

15. Boehrer, B., von Rohden, C. \& Schultze, M. Physical Features of Meromictic Lakes: Stratification and Circulation. In: Gulati, R., Zadereev, E., Degermendzhi, A. (eds) Ecology of Meromictic Lakes. Ecological Studies (Analysis and Synthesis), 228, (Springer, Cham, 2017).

16. Lewis, W. M., Jr. A revised classification of lakes based on mixing. Can. J. Fish. Aquat. Sci. 40, 1779-1787 (1983).

17. Dee, D. P. et al. The ERA-Interim reanalysis: configuration and performance of the data assimilation system. Q. J. R. Meteorol. Soc. 137, 553-597 (2011).

18. Verpoorter, C. et al. A global inventory of lakes based on high-resolution satellite imagery. Geophys. Res. Lett. 41, 6396-6402 (2014).

19. Messager, M. L. et al. Estimating the volume and age of water stored in global lakes using a geo-statistical approach. Nat. Commun. 7, 13603 (2016).

20. Mironov, D. Parameterization of lakes in numerical weather prediction: Part 1. Description of a lake mode. COSMO Technical Report, No. 11, Deutscher Wetterdienst, Offenbach am Main, Germany, (2008).

21. Mironov, D. et al. Implementation of the lake parameterisation scheme FLake into the numerical weather prediction model COSMO. Boreal Environ. Res. 15, 218-230 (2010).

22. Frieler, K. et al. Assessing the impacts of $1.5^{\circ} \mathrm{C}$ global warming - simulation protocol of the Inter-Sectoral Impact Model Intercomparison Project (ISIMIP2b). Geosci. Model Dev. 10, 4321-4345 (2017).

23. Regier, H. A., Holmes, J. A. \& Pauly, D. Influence of temperature changes on aquatic ecosystems: an interpretation of empirical data. Trans. Am. Fish. Soc. 119, 374-389 (1990).

24. Mortimer, C. H. The exchange of dissolved substances between mud and water in lakes, J. Ecol. 29, 280-329 (1941).

25. Davison, W. Supply of iron and manganese to an anoxic lake basin, Nature 290, 241-243 (1981).

26. Weyhenmeyer, G. A., Westöö, A.-K. \& Willén, E. Increasingly ice-free winters and their effects on water quality in Sweden's largest lakes. Hydrobiologia 599, 111-118 (2008).

27. Weyhenmeyer, G. A., Bleckner, T. \& Petterson, K. Changes of the plankton spring outburst related to the North Atlantic Oscillation. Limnol. Oceanogr. 44, 1788-1792 (1999).

28. Woolway, R. I., Meinson, P., Nöges, P., Jones, I. D. \& Laas, A. Atmospheric stilling leads to prolonged thermal stratification in a large shallow polymictic lake. Clim. Change, 141, 759-773 (2017).

29. Rosenberry, D O. et al. Groundwater - the disregarded component in lake water and nutrient budgets. Part 1: effects of groundwater on hydrology. Hydrol. Process. 29, 28952921 (2015). 
30. Peter, H., \& Sommaruga, R. Alpine glacier-fed turbid lakes are discontinuous cold polymictic rather than dimictic. Inland Waters 7, 45-54 (2017).

31. Kirillin, G., Shatwell, T. \& Kasprzak, R. Consequences of thermal pollution from a nuclear plant on lake temperature and mixing regime. J. Hydrol. 496, 47-56 (2013).

32. Valerio, G., Pilotti, M., Barontini, S. \& Leoni, B. Sensitivity of the multiannual thermal dynamics of a deep pre-alpine lake to climatic change. Hydrol. Processes 29, 767-779 (2015).

33. Rimmer, A., Gal, G., Opher, T., Lechinsky, Y.\& Yacobi, Y. Z. Mechanisms of longterm variations in the thermal structure of a warm lake. Limnol. Oceanogr. 56, 974-988 (2011).

34. Shatwell, T., Adrian, R. \& Kirillin, G. Planktonic events may cause polymictic-dimictic regime shifts in temperate lakes. Sci. Rep. 6, 24361(2016).

35. Fee, E. J., Hecky, R. E., Kasian, S. E. M. \& Cruikshank, D. R. Effects of lake size, water clarity, and climatic variability on mixing depths in Canadian Shield lakes. Limnol. Oceanogr. 41, 912-920 (1996).

36. Read, J. S. \& Rose, K. C. Physical responses of small temperate lakes to variation in dissolved organic carbon concentrations. Limnol. Oceanogr. 58, 921-931 (2013).

37. Gorham, E. \& Boyce, F. M. Influence of lake surface area and depth upon thermal stratification and the depth of the summer thermocline. J. Great Lakes Res. 15, 233-245 (1989).

38. Kainz, M. J., Ptacnik, R., Rasconi, S. \& Hager, H. H. Irregular changes in lake surface water temperature and ice cover in subalpine Lake Lunz, Austria. Inland Waters 7, 27-33 (2017).

39. Ficker, H., Luger, M. \& Gassner, H. From dimictic to monomictic: Empirical evidence of thermal regime transitions in three deep alpine lakes in Austria induced by climate change. Freshwater Biol. 62, 1335-1345 (2017).

\section{Acknowledgements}

This analysis was funded by EUSTACE (EU Surface Temperature for All Corners of Earth) which has received funding from the European Union's Horizon 2020 Programme for Research and Innovation, under Grant Agreement no 640171. The authors also acknowledge the European Space Agency funding of the ARC-Lake project. We thank Martin Dokulil for providing lake temperature data for Mondsee and Wörthersee. RIW received funding from a European Union's Marie Skłodowska-Curie Individual Fellowship (\#791812; INTEL project). This work benefited from participation in the Global Lake Ecological Observatory Network (GLEON).

\section{Author Contributions}

Both authors developed the concept of the study, designed the analytical experiments, interpreted the results and wrote the paper.

\section{Financial and non-financial competing interests}

The authors do not have any competing financial or non-financial interests to declare. 


\section{Figure captions}

Figure 1. Global patterns in annual mean (1995-2005) ice cover duration, lake surface temperature and lake mixing regimes. (a) Satellite-derived ice cover duration and (b) their relationship with air temperature (from ERA-Interim ${ }^{17}$ ). (c) Global variations in satellitederived lake surface water temperature and (d) their relationship with latitude and elevation. (e) Global variations in modelled lake mixing regimes and (f) their relationship with latitude and lake surface water temperature. Mixing regimes were identified using the classification scheme of ref. 16, extended to include an oligomictic class, evaluated from a lake model forced by bias-corrected HadGEM2-ES projections. (Lake mixing regimes identified while using bias-corrected projections from other climate models are shown in Fig. S8).

Figure 2. Global changes (2080-2100 relative to $1985-2005)$ in annually averaged ice cover duration and lake surface water temperature. (a) Changes in ice cover duration under RCP 2.6 and 6.0 (shown only for northern hemisphere lakes) from a lake model forced with bias-corrected HadGEM2-ES projections, and (b) all climate model projections from ISIMIP2b, showing also the kernel density estimates (horizontal widths of coloured areas). Changes are also shown for the annual average lake surface temperature under (c-d) RCP 2.6 and (E-F) RCP 6.0, showing results from the lake model forced with HadGEM2-ES projections (c and e) as well as all models ( $d$ and $f$ ). In Figs 2b, 2d, 2f, the mean and standard deviation is also shown (black).

Figure 3. Global changes (2080-2100 relative to $1985-2005)$ in lake mixing regimes. Shown are climate-related changes in lake mixing regimes under (a) RCP 2.6 and (b) RCP 6.0 using a lake model forced with bias-corrected HadGEM2-ES projections (comparison of lake mixing regime alterations identified while using bias-corrected climate projections from other climate models are shown in Figs S9-S10). Every lake that experiences a mixing regime alteration is shown in grey in the maps and the most frequent mixing regime alterations (encompassing $80 \%$ of the identified mixing regime shifts) are shown with individual colours (see legend). 
Projected global mixing regime alterations
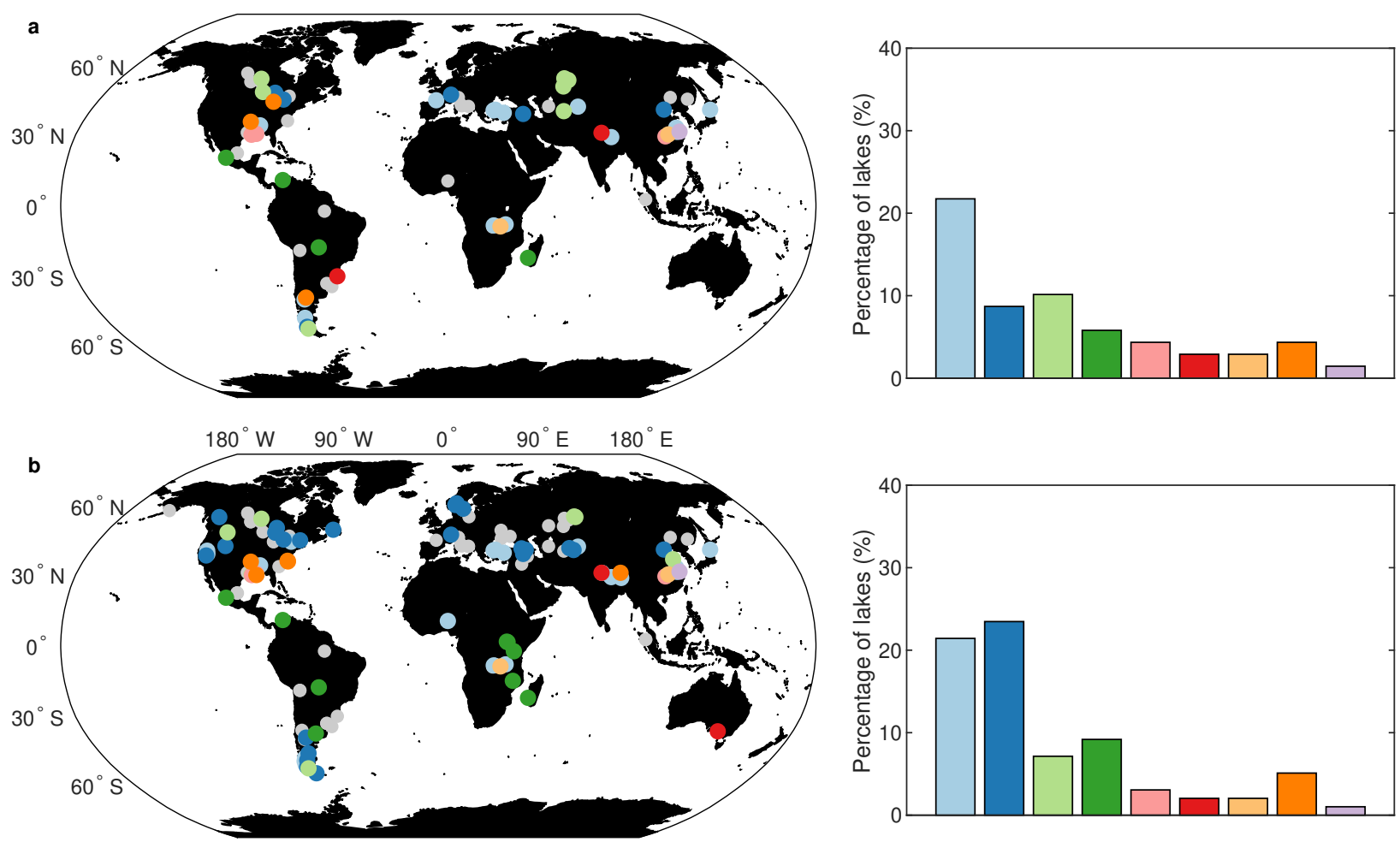
$180^{\circ} \mathrm{W}$
$90^{\circ} \mathrm{W}$
$0^{\circ}$
$90^{\circ} \mathrm{E} \quad 180^{\circ} \mathrm{E}$

Warm Mono. - Meromictic

Dimictic - Warm Mono.

Cont. Warm Poly. - Disc. Warm Poly.

Disc. Col. Poly. - Disc. Warm Poly.

Disc. Warm Poly. - Warm Mono.

Disc. Warm Poly. - Meromictic

Dimictic - Disc. Warm Poly.

Disc. Cold Poly. - Dimictic

Disc. Cold Poly. - Warm Mono. 


\section{Methods}

Methods, including statements of data availability and any associated references, are available in the online Methods.

\section{Online Methods}

Study sites - The lakes investigated in this study $(n=635)$ vary in their geographic and morphological characteristics (Table S1).

Satellite-derived lake temperature and ice cover data - We utilize lake surface temperatures from the ATSR (Along Track Scanning Radiometer) Reprocessing for Climate: Lake Surface Water Temperature and Ice Cover (ARC-Lake) dataset ${ }^{40}$, available at http://www.laketemp.net. In outline, the ARC-Lake surface water temperatures were obtained as follows. Within prescribed lake boundaries a water-detection algorithm using the reflectance channels of the ATSR-2 and AATSR instruments was applied to determine the extent of each lake during the ATSR-2/AATSR period. Within these boundaries, a Bayes' theorem calculation of the probability of clear sky conditions was performed for each image pixel, day and night ${ }^{41}$. For pixels with high clear-sky probability, the lake surface water temperature was retrieved from the ATSR-2/AATSR thermal imagery, using an optimal estimation method adapted from radiative-transfer physics-based techniques extensively validated for sea surface temperature ${ }^{42}$. Temperature estimates were gridded and spatiotemporally gap-filled using dynamically interpolating empirical orthogonal functions ${ }^{43}$. For a fuller account, refer to ref. 40. Daily lake-mean time-series were obtained by averaging across the lake area. Lake-mean surface temperatures are used in order to average across the intra-lake heterogeneity of surface water temperature responses to climate change ${ }^{44}$ and to correspond to the lake-mean model used (see below).

The effectiveness of the lake product retrieval algorithms in ARC-Lake has previously been assessed using a dataset of matches to in situ temperature data, consisting of 52 observation locations covering 16 lakes and $>5,500$ individual matches ${ }^{40}$. Overall, agreement was $-0.2 \pm 0.7 \mathrm{~K}$ for daytime and $-0.1 \pm 0.5 \mathrm{~K}$ for night-time matches. ARC-Lake data have been independently validated as part of other studies ${ }^{45}$ and used to validate lake simulations ${ }^{46,47}$. In this study we use daily averaged LSWTs, calculated as the average of the day and night-time retrievals. To assess from the daily-mean temperature time-series the periods during which a lake was likely partially or wholly ice covered, we follow ref. 48, and characterise this as the period during which the lake-mean surface water temperature is $<1^{\circ} \mathrm{C}$. This corresponds closely to presence of lake ice cover from in-situ observations ${ }^{48}$.

The ARC-Lake observations were also used to quantify global patterns in mean lake temperatures and as part of the validation (see below) of the modelled surface temperatures and ice cover duration in lakes globally (Fig. S2, Fig. S5).

Lake model - To simulate depth-resolved lake temperatures, as required to identify mixing regimes in lakes, we used the one-dimensional thermodynamic lake model FLake ${ }^{20}$, ${ }^{21}$. FLake is a simplified lake model that is in some instances less accurate than other more computationally expensive models ${ }^{49}$, but which can be efficiently coupled with climate models and is useful for evaluating the impact of climate change projections on lakes ${ }^{45}$. FLake is used widely both for research and as a component in numerical weather prediction ${ }^{50}$, 
51. It has been tested extensively in past studies, including detailed validations across a spectrum of lake contexts. FLake has been used previously for validated simulation of the vertical temperature profile as well as changes to the mixing regime of polymictic and dimictic lakes ${ }^{34,52-53}$, and has been shown to reproduce accurately bottom water temperatures as well as the depth and seasonality of the upper mixed layer and thermocline in meromictic $\operatorname{lakes}^{45,54,55}$. The model has also been used to reproduce past variability in ice cover timing, intensity and duration ${ }^{56}$, and to investigate the thermal response of polymictic, monomictic and lakes to large-scale climatic shifts ${ }^{57}$. The integrated approach implemented in FLake allows a realistic representation of the major physics behind turbulent and diffusive heat exchange in lakes, including a module to describe the vertical temperature structure of the thermally active layer of bottom sediments, as well as its interaction with the water column above. The lakes investigated in this study all have depths $<60 \mathrm{~m}$, an established criterion for applicability of the FLake model in global studies ${ }^{46,50}$, except that deeper lakes are included for which we had independent validation of the lake model's ability to simulate mixing regime (Table $\mathrm{S} 1$ ).

The meteorological variables required to drive FLake are air temperature at $2 \mathrm{~m}$, wind speed at $10 \mathrm{~m}$, surface solar and thermal radiation, and specific humidity. Lake specific parameters must be set to simulate individual lakes optimally in FLake. These parameters comprise fetch (m), which we fix in this study to the square root of lake surface area, lake depth $(\mathrm{m})$, lake ice albedo and the light attenuation coefficient $\left(\mathrm{K}_{\mathrm{d}}, \mathrm{m}^{-1}\right)$.

The prognostic variables needed to initialise FLake simulations include (i) mixed layer temperature, (ii) mixed layer depth, (iii) bottom temperature, (iv) mean temperature of the water column, (v) temperature at the ice (if present) upper surface and (vi) ice thickness (if present). In order to initialise the model runs from physically reasonable fields, we initialise runs from a perpetual-year solution for the lake state. To find this solution for the initialisation state, the model parameters are set as follows: mean depth was extracted from the Hydrolakes database ${ }^{19}$, which include observational and geo-statistical model estimates of lake depths worldwide; $\mathrm{K}_{\mathrm{d}}$ was set to $3 \mathrm{~m}^{-1}$ (ref. 50); lake ice albedo was set to 0.6 (ref. 21). The perpetual-year solution is obtained by repeating the forcing from a representative year and running FLake until the annual cycle in modelled lake state is stabilised. The forcing data to derive the initialisation conditions are from the ERA-Interim reanalysis product ${ }^{17}$, available at a latitude-longitude resolution of $0.75^{\circ}$.

To optimize FLake simulations for each lake, we then use the model-tuning algorithm of ref. 58. This approach estimates the model parameters (lake depth, $\mathrm{K}_{\mathrm{d}}$, and ice albedo; Table S1) to reproduce optimally the observed surface temperature dynamics, specifically by minimising the mean square differences between model and ARC-Lake surface water temperature over the satellite period (1995-2011), in simulations initialised from the perpetual year solution described above. The lake-specific parameters for the model are thus set without reference to any in situ data or to the climate model forcing fields used for historical-period simulation and future projections (see below). Note that while the optimisation is based solely on surface temperature, energy budget considerations suggest that there is some calibration of the temperature profile features, such as development of the thermocline depth, that need to be well represented in order for the surface temperature evolution over time to be calibrated successfully. It is a significant strength of the analysis that the FLake model can be optimised using only surface temperatures and then diagnose 
successfully the mixing classification of many lakes in which this information was independently available (see below).

Simulations forced by climate model projections - To drive FLake and evaluate lake temperature, ice cover, and mixing regime responses to climate change, we use bias-corrected climate model projections from the Inter-Sectoral Impact Model Intercomparison Project (ISIMIP2b), specifically using projections from GFDL-ESM2M, HadGEM2-ES, IPSLCM5A-LR, and MIROC5 for historic (1911-2005) and future periods (2081-2100) under two scenarios: RCP 2.6 and RCP 6.0. These pathways encompass a range of potential future global radiative forcing from anthropogenic greenhouse gases and aerosols, and results span a range of potential impacts on lake temperature, ice cover, and mixing regimes. Other commonly used RCP scenarios, RCP 4.5 and RCP 8.5, are not included in ISIMIP2b as they were either considered too high for evaluating future climate impacts (RCP 8.5) or to not provide enough span (RCP 4.5).

We downloaded the data needed to drive FLake from ISIMIP2b (https://www.isimip.org/protocol/\#isimip2b), including projections of air temperature at $2 \mathrm{~m}$, wind speed at $10 \mathrm{~m}$, surface solar and thermal radiation, and specific humidity, which were available at a daily time step and at a grid resolution of $0.5^{\circ}$. Time series data were extracted for the grid point situated closest to the centre of each lake, defined as the maximum distance to land, calculated using the distance-to-land dataset of ref. 59.

To verify that FLake, driven by the climate model projections, is able to simulate multi-decadal variations in lake surface temperature (and can therefore be informative with respect to future climate change impacts), we compared the FLake simulations from 1915 to 2005 with in-situ measurements from two European lakes, Mondsee and Wörthersee. Lake surface temperature data from these lakes were extracted from the yearbooks of the hydrographic service Austria (https://www.bmlfuw.gv.at/wasser/wasseroesterreich/wasserkreislauf/hydrographische_daten/jahrbuecher.html). Each of the lakes were sampled daily at a depth of $\sim 0.2 \mathrm{~m}$ at the lake-level gauging station. This sampling was performed between 08:00 and 10:00 throughout the observational period, thus limiting the inconsistencies introduced by sampling at different times during a diel cycle, which in some lakes can be very large ${ }^{60}$. Lake temperature simulations, using each of the four model projections in ISIMIP2b, show coherence with inter-annual variability on multi-decadal scales (Fig. S4). Further comparisons of this nature on more widespread lakes would give even greater confidence in long-term simulations, but we were unable to source consistent in situ observations of this length for other lakes.

Modelled summer average lake surface temperature driven by the climate model data were also compared with in-situ summer-average lake surface temperatures $(n=19)$ from ref. 61, including data from Baikal, Lake Biwa, Bodensee, Lake Erie, Sea of Galilee, Lake Garda, Lac Léman, Lake Huron, Lake Michigan, Neusiedler See, Peipsi, Saimaa, Lake Superior, Lake Tahoe, Lake Taihu, Lake Tanganyika, Lake Taupo, Vänern and Vättern (Fig S3).

Simulated lake ice cover duration was validated against ARC-Lake estimates (Fig. S5) of ice cover duration using the proxy measure of the sustained $<1^{\circ} \mathrm{C}_{\text {period }}{ }^{48}$. The proxy measure of ice cover was also compared with directly observed ice cover duration from the Global Lake and River Ice Phenology Database ${ }^{62}$ (Fig. S6). To illustrate the accuracy of the proxy metric, the observed ice cover duration was also compared against the simulated period 
of non-zero ice thickness from the FLake model (Fig. S6). We compared the climatological durations of ice cover in model and observations. The latter comparison requires lakes that were available in both the ARC-Lake dataset (and thus were simulated by FLake) as well as in the Global Lake and River Ice Phenology Database for a substantially overlapping time period. Thirteen such lakes were available. The modelled average number of ice-covered days agreed well with those observed (Fig. S6).

Climate-related impacts are assessed as the difference in mean lake conditions (e.g., mean lake temperature, mean number of ice-covered days, and identified mixing regime) between the period 1985-2005 ('historic' period) and 2080-2100 ('future' period).

Lake mixing class - To classify lakes according to their mixing regimes, during both the historic and future periods, we apply the commonly used classification scheme of ref. 16 . The terminology of lake mixing regimes is determined by (i) whether a lake experiences ice cover, and (ii) how many times a lake's water column mixes vertically on an annual basis. Lewis produced a flow diagram describing how to identify a lake's mixing regime (Fig. S1). Lewis' classification scheme identifies five main lake mixing types: amictic, polymictic, monomictic, dimictic, and meromictic. In brief, amictic lakes are those that are persistently ice covered; polymictic lakes are those that mix frequently; monomicitc lakes experience one vertical mixing event per year, typically in winter when the vertical temperature difference within a lake is close to zero; dimictic lakes experience two mixing events per year, one following the summer stratified period and the other following the inversely stratified winter period; and meromictic lakes are those that are persistently stratified. Polymictic lakes can be divided further into discontinuous or continuous polymictic, the latter representing a lake that mixes daily. Monomictic and dimictic lakes can be separated further into 'cold' or 'warm' lakes depending on whether or not they experience ice cover annually. Lewis' classification scheme, according to the above definitions, identifies nine mixing regime types: meromictic, warm monomictic, discontinuous warm polymictic, continuous warm polymictic, amictic, cold monomictic, dimictic, discontinuous cold polymictic, and continuous cold polymictic (Fig. S1). In addition to the nine mixing regime types identified by ref. 16 we also distinguish oligomictic lakes in the global classification. Oligomictic lakes are those that are persistently stable in most years, yet completely mix in some years.

To determine which mixing regime a lake belongs to according to their vertical temperature profiles, we follow ref. 63-65 and characterise a lake as being mixed when the difference (absolute) between its surface temperature and that at depth (i.e., bottom temperature) is less than $1^{\circ} \mathrm{C}$. This is evaluated from the modelled lake temperatures (i.e., depth-resolved) during the historic and future periods. As an example, we would define a dimictic lake as a lake that (i) experiences winter ice cover, (ii) has an ice-free period, (iii) warms above $4^{\circ} \mathrm{C}$ with regards to its surface temperature and (iv) experiences two mixing periods within a given year (Fig. S1). For each lake, we determine the mixing class for each year, and assign the overall mixing class to be the dominant model mixing class for the historic and future periods. To differentiate oligomictic and meromictic lakes, all years during each historic or future periods are used to assess whether the lake mixes occasionally. Annual mixing classes are generally consistent across a period: $80 \%$ of lakes have the same class for $>15$ of the 20 years of the historic period, for example. 
To validate the modelled lake mixing regimes during the historic period, as simulated by FLake driven by each ISIMIP2b model run, we compared results with literature-derived descriptions from 85 lakes, including those described by ref. 66-69, and the World Lake Database (Table S2). In these comparisons we did not separate mixing regimes within an individual class. For example, we did not distinguish between cold and warm monimictic and continuous and discontinuous polymictic, as this information was not available frequently in the literature. Lake mixing regimes assessed from the FLake simulations were in agreement with those from these sources in $72 \%$ of cases for three of the ISIMIP2b model runs (Fig. S7) and $73 \%$ for the other (IPSL-CM5A-LR).

\section{Data availability}

Satellite lake temperature data are available at http://www.laketemp.net. Observed lake surface temperature data are available at https://portal.lternet.edu/nis/mapbrowse?packageid=knb-lter-ntl.10001.3. Climate model projections are available at https://www.isimip.org/protocol/\#isimip2b.

\section{Code availability}

The lake model source code is available to download from http://www.flake.igb-berlin.de/.

\section{References only in Methods}

40. MacCallum, S. N., \& Merchant, C. J. Surface water temperature observations of large lakes by optimal estimation. Can. J. Remote Sens. 38, 25-44 (2012).

41. Merchant, C. J., Harris, A. R., Maturi, E. \& MacCallum, S. Probabilistic physically based cloud screening of satellite infrared imagery for operational sea surface temperature retrieval. Q. J. R. Meteorol. Soc. 131, 2735-2755 (2005).

42. Merchant, C. J., Le Borgne, P., Marsouin, A. \& Roquet, H. Optimal estimation of sea surface temperature from split-window observations. Remote Sens. Environ. 112, 24692484 (2008).

43. Alvera-Azcárate, A., Barth, A., Rixen, M. \& Beckers, J. M. Reconstruction of incomplete oceanographic data sets using empirical orthogonal functions: application to the Adriatic Sea surface temperature. Ocean Model. 9, 325-346 (2005)

44. Woolway, R. I. \& Merchant, C. J. Intra-lake heterogeneity of lake thermal responses to climate change: A study of large Northern Hemisphere lakes. J. Geophys. Res. Atmospheres 123, 3087-3098 (2018)

45. Thiery, W., et al., The impact of the African Great Lakes on the regional climate. $J$. Climate 28, 4061-4085 (2015).

46. Le Moigne, P. et al. Impact of lake surface temperatures simulated by the FLake scheme in the CNRM-CM5 climate model. Tellus A 68 (2016).

47. Verseghy, D. L. \& MacKay, M. D. Offline implementation and evaluation of the Canadian small lake model with the Canadian land surface scheme over Western Canada. J. Hydrometeorol. 18, 1563-1582 (2017).

48. Layden, A., Merchant, C. J. \& MacCallum, S. Global climatology of surface water temperatures of large lakes by remote sensing. Int. J. Climatol. 35, 4464-4479 (2015).

49. Stepanenko, V. M. et al. First steps of a Lake Model Intercomparison Project: LakeMIP. Boreal Environ. Res. 15, 191-202 (2010). 
50. Balsamo, G. et al. On the contribution of lakes in predicting near-surface temperature in a global weather forecasting model. Tellus A 64, 15829 (2012).

51. Rooney, G. \& Jones, I. D. Coupling the 1-D lake model FLake to the community landsurface model JULES. Boreal Environ. Res. 15, 501-512 (2010)

52. Kirillin, G. Modeling the impact of global warming on water temperature and seasonal mixing regimes in small temperate lakes. Boreal Environ. Res. 15, 279-293 (2010).

53. Kirillin, G., Shatwell, T. \& Kasprzak, R. Consequences of thermal pollution from a nuclear plant on lake temperature and mixing regime. J. Hydrol. 496, 47-56 (2013).

54. Thiery, W. et al. Understanding the performance of the FLake model over two African Great Lakes. Geosci. Model Dev. 7, 317-337 (2014).

55. Thiery, W. et al. Hazardous thunderstorm intensification over Lake Victoria. Nat. Commun. 7, 12786 (2016).

56. Bernhardt, J. et al. Lake ice phenology in Berlin-Brandenburg from 1947-2007: observations and model hindcasts. Clim. Change 112, 791-817 (2012).

57. Woolway, R. I. et al. Warming of Central European lakes and their response to the 1980s climate regime shift. Clim. Change 142, 505-520 (2017)

58. Layden, A., MacCallum, S. N. \& Merchant, C. J. Determining lake surface water temperatures worldwide using a tuned one-dimensional lake model (Flake, v1). Geosci. Model Dev. 9, 2167-2189 (2016).

59. Carrea, L., Embury, O. \& Merchant, C. J. Datasets related to in-land water for limnology and remote sensing applications: Distance-to-land, distance-to-water, water-body identifier and lake-centre co-ordinates. Geosci. Data J. 2, 83-97 (2015).

60. Woolway, R. I. et al. Diel surface temperature range scales with lake size. PLoS ONE. 11, e0152466 (2016).

61. Sharma, S. et al. A global database of lake surface temperatures collected by in situ and satellite methods from 1985-2009. Sci. Data 2, 150008 (2015).

62. Benson, B. \& Magnuson, J. J. Global Lake and River Ice Phenology Database, Version 1, Boulder, Colorado USA. NSIDC: National Snow and Ice Data Center [15/01/2018] (2000).

63. Stefan, H. G., Hondzo, M., Fang, X., Eaton, J. G. \& McCormick, J. H. Simulated longterm temperature and dissolved oxygen characteristics of lakes in the north-central United States and associated fish habitat limits. Limnol. Oceanogr. 41, 1124-1135 (1996).

64. Read, J. S. et al. Simulating 2368 temperate lakes reveals weak coherence in stratification phenology. Ecol. Modell. 291, 142-150 (2014).

65. Woolway, R. I., Maberly, S. C., Jones, I. D. \& Feuchtmayr, H. A novel method for detecting the onset of thermal stratification in lakes from surface water measurements. Water Resour. Res. 50, 5131-5140 (2014).

66. Herdendorf, C. E. Distribution of the world's large lakes, pp 3-38, in Tilzer, MM, Serruya C, eds. Large Lakes: Ecological Structure and Function (Springer-Verlag, Berlin, 1990).

67. Titze, D. J. \& Austin, J. A. Winter thermal structure of Lake Superior. Limnol. Oceanogr. 59, 1336-1348 (2011).

68. Katsev S., Verburg, P., Llirós, M., Minor, E. C., Kruger, B. R. \& Li, J. Tropical Meromictic Lakes: Specifics of Meromixis and Case Studies of Lakes Tanganyika, 

Meromictic Lakes. Ecological Studies (Analysis and Synthesis) (Springer, Cham, 2017). 69. Syarki, M. T. \& Tekanova, E. V. Seasonal primary productivity cycle in Lake Onega. Biology Bulletin 35, 536-540 (2008). 
Supporting information for

\title{
Worldwide alteration of lake mixing regimes in response to climate change
}

\author{
R. Iestyn Woolway ${ }^{1 *}$, Christopher J. Merchant ${ }^{1,2}$
}

1. Department of Meteorology, University of Reading, Reading, UK

2. National Centre for Earth Observation, University of Reading, Reading, UK

*now at Dundalk Institute of Technology, Dundalk, Ireland

\section{Introduction}

The supporting information presented here provides more comprehensive details that complement the analyses presented in the main text, allowing a more complete assessment of our findings.

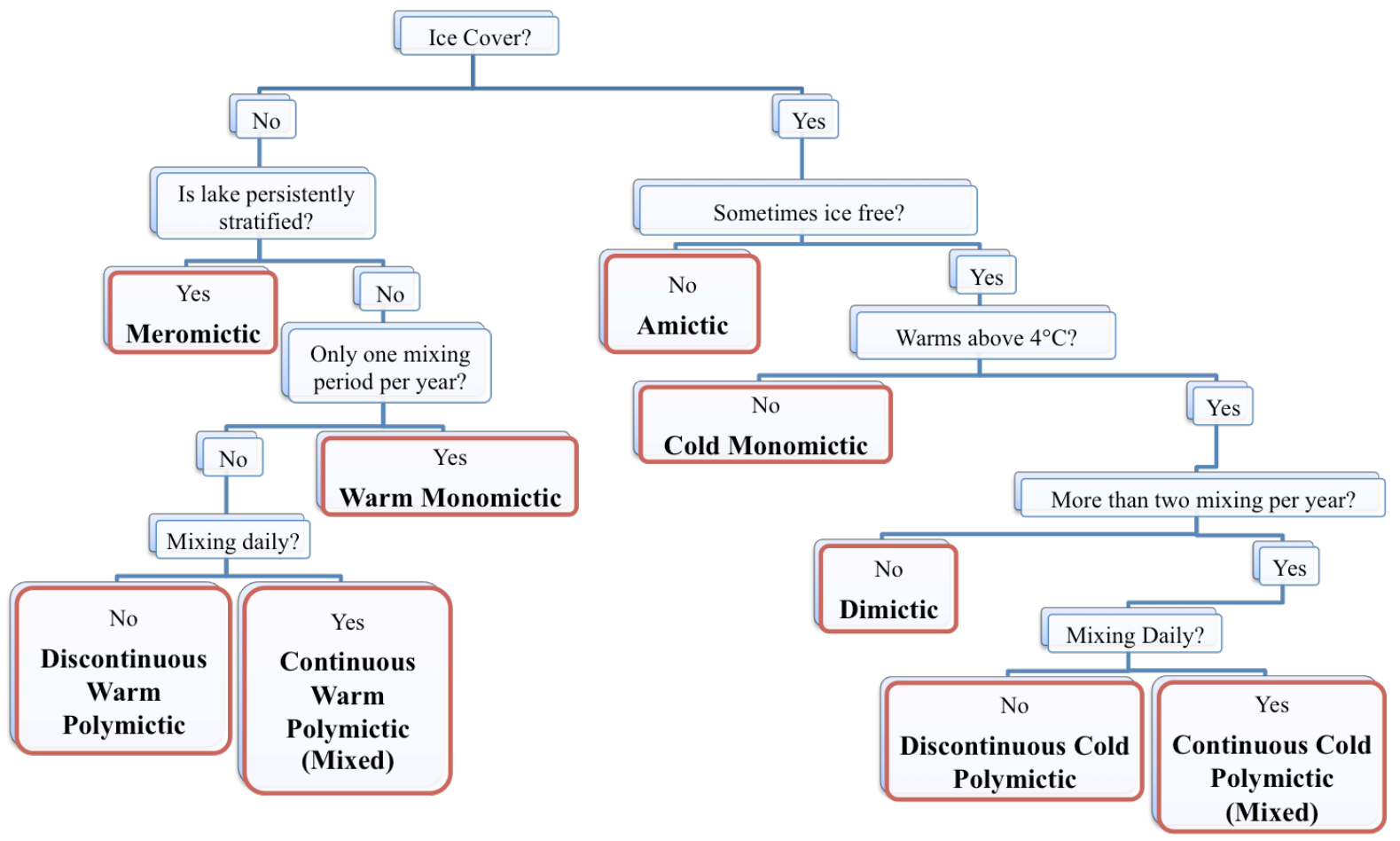

Figure S1. Classification scheme used in this study to determine the mixing regimes of lakes. Modified from ref. 16. The criteria used to define a stratified (or mixed) period is when the top minus bottom (modelled) lake temperature difference (absolute) exceeds (or is lower than) $1{ }^{\circ} \mathrm{C}$ (see Methods). To assess from the lake surface temperatures (observed or modelled) the period during which a lake is likely ice covered, we follow ref. 48 , and characterise this as the period during which the lake-mean surface water temperature is $<1{ }^{\circ} \mathrm{C}$ (see Methods). In addition to the nine mixing regime types identified by ref. 16 we also include oligomictic lakes in the mixing regime classification. Oligomictic lakes are almost persistently stable, mixing only rarely. Specifically, oligomictic lakes do not mix every year but still completely mix in some years. 

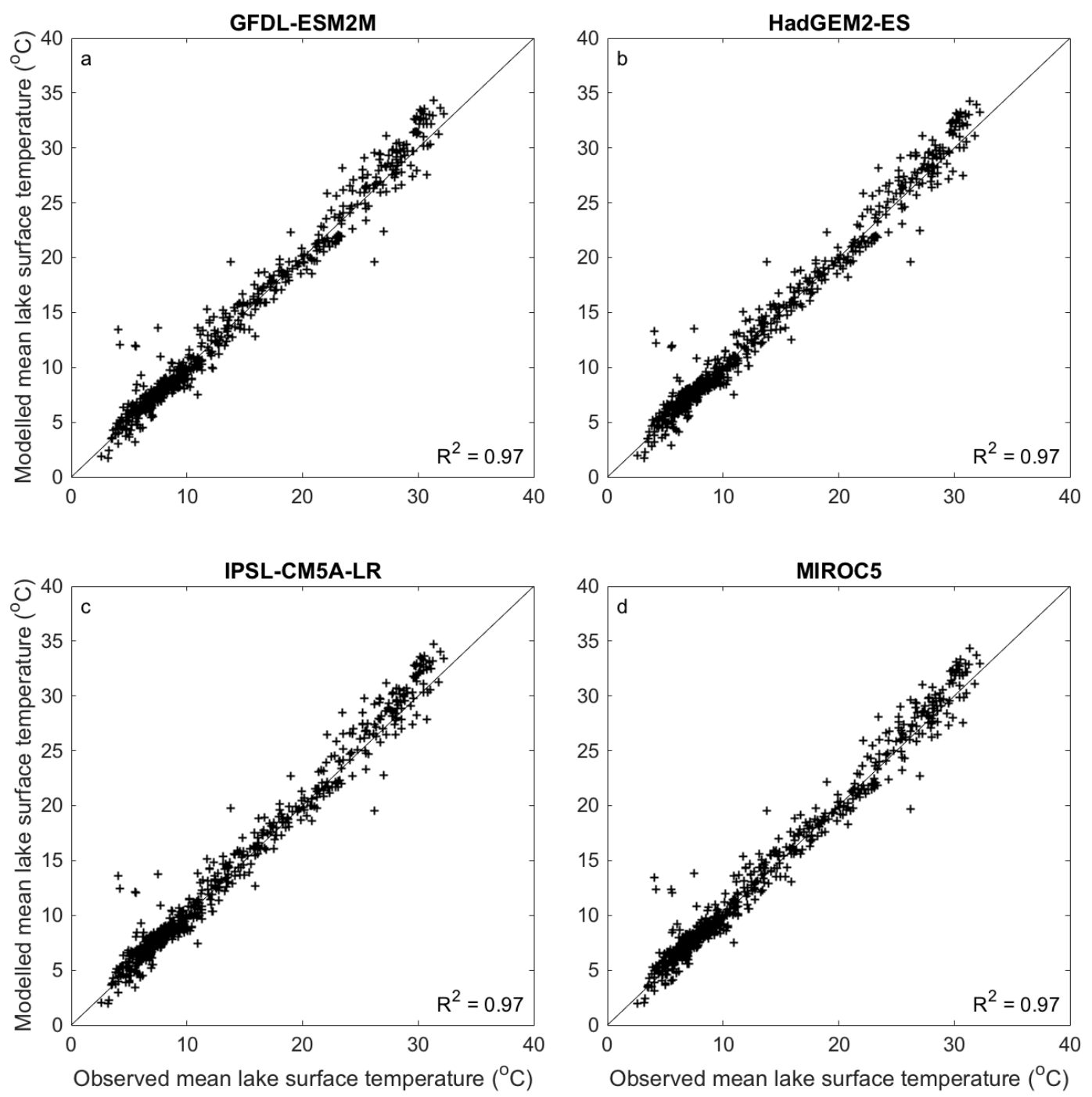

Figure S2. Comparison of annual mean (1995-2005) modelled and observed satellite-derived lake surface water temperatures for 635 lakes in which lake temperature data were available and used in this study. The modelled lake temperatures represent those simulated by a lake model forced with biascorrected climate projections available from the Inter-Sectoral Impact Model Intercomparison Project, namely (A) GFDL-ESM2M, (B) HadGEM2-ES, (C) IPSL-CM5A-LR and (D) MIROC5. Time series data needed to drive the lake model from each climate projection were extracted for the grid point situated closest to the centre of each lake. 

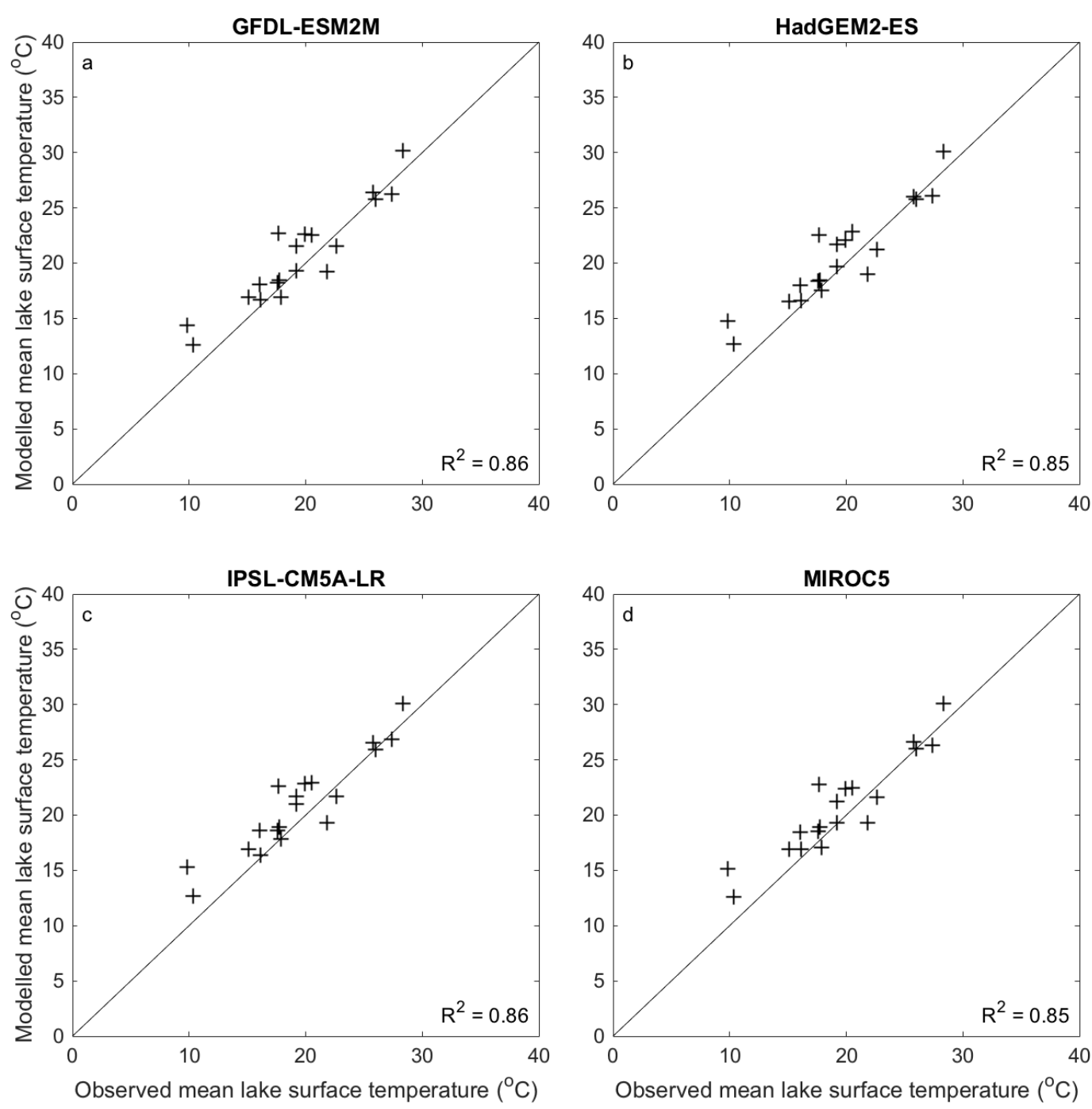

Figure S3. Comparison of summer-average modelled and observed lake surface water temperatures. In-situ summer-average lake surface temperatures are from ref. 61 and include data from Baikal, Lake Biwa, Bodensee, Lake Erie, Sea of Galilee, Lake Garda, Lac Léman, Lake Huron, Lake Michigan, Neusiedler See, Peipsi, Saimaa, Lake Superior, Lake Tahoe, Lake Taihu, Lake Tanganyika, Lake Taupo, Vänern and Vättern. Modelled lake surface temperatures represent those simulated by a lake model forced with bias-corrected climate projections available from the Inter-Sectoral Impact Model Intercomparison Project, namely (A) GFDL-ESM2M, (B) HadGEM2-ES, (C) IPSL-CM5A-LR and (D) MIROC5. Time series data needed to drive the lake model from each climate projection were extracted for the grid point situated closest to the centre of each lake. 

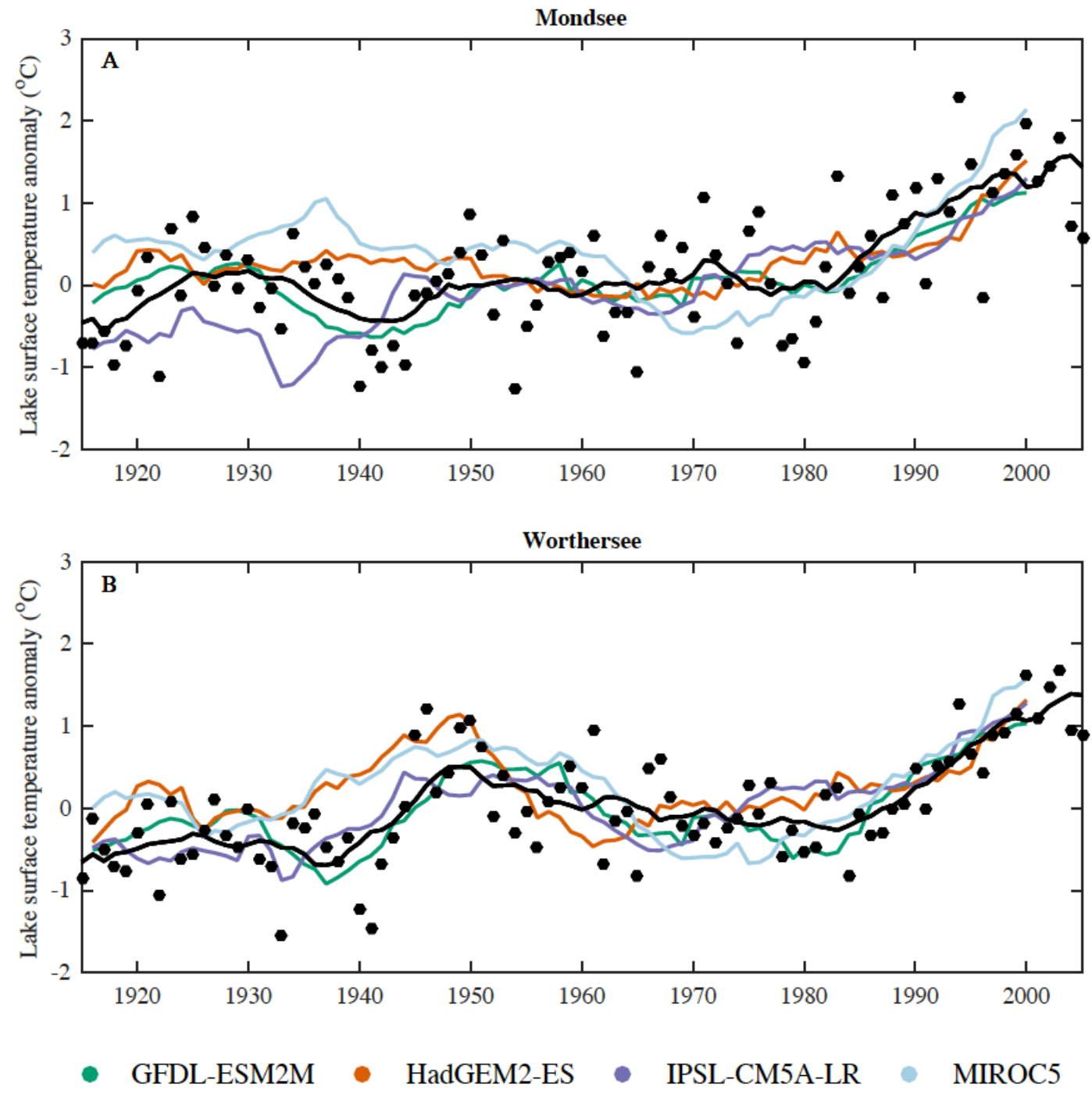

Figure S4. Comparison of observed (black) and modelled (colour) annual mean lake surface temperature anomalies from 1915 to 2005. Modelled lake surface temperatures represent those simulated by a lake model forced with bias-corrected climate projections available from the InterSectoral Impact Model Intercomparison Project, namely, GFDL-ESM2M (green), HadGEM2-ES (orange), IPSL-CM5A-LR (purple) and MIROC5 (blue). Comparisons are shown for two European lakes (Mondsee and Wörthersee), for which long-term in-situ lake surface temperatures were available. Lake temperatures are shown as annual averages (observed; black points) and with an 11-year moving average (solid lines). All temperatures are shown as anomalies relative to 1951-1980. Time series data needed to drive the lake model from each climate projection were extracted for the grid point situated closest to the centre of these lakes. 

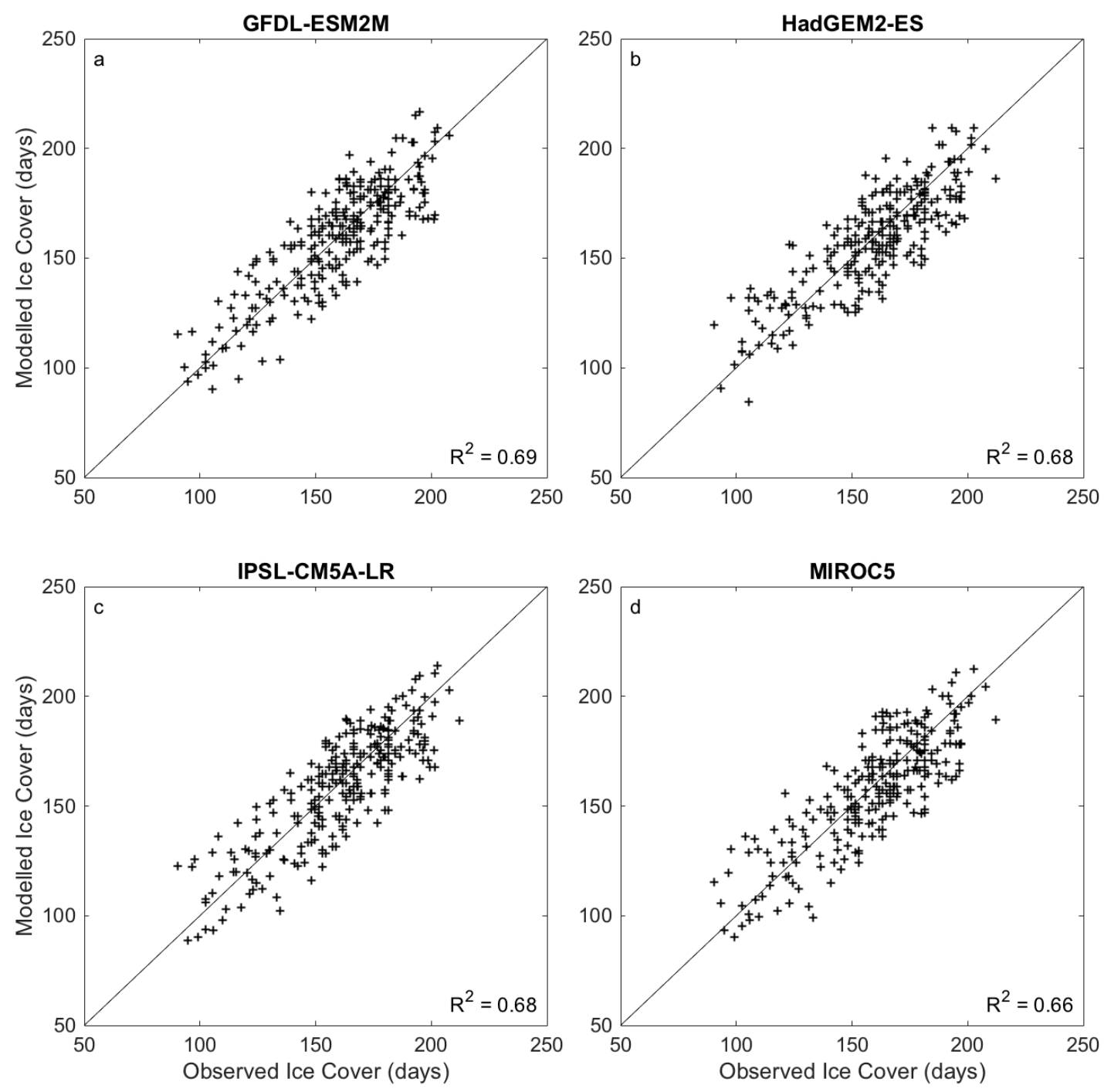

Figure S5. Comparison of modelled and observed (1995-2005) ice cover duration (in days) for the studied lakes which experienced ice cover. The modelled lake temperatures represent those simulated by a lake model forced with bias-corrected climate projections available from the Inter-Sectoral Impact Model Intercomparison Project, namely (A) GFDL-ESM2M, (B) HadGEM2-ES, (C) IPSL-CM5A-LR and (D) MIROC5. Time series data needed to drive the lake model from each climate projection were extracted for the grid point situated closest to the centre of each lake. To assess from the lake surface temperatures (observed or modelled) the period during which a lake is likely ice covered, we follow ref. 48, and characterise this as the period during which the lake-mean surface water temperature is $<1^{\circ} \mathrm{C}$. 

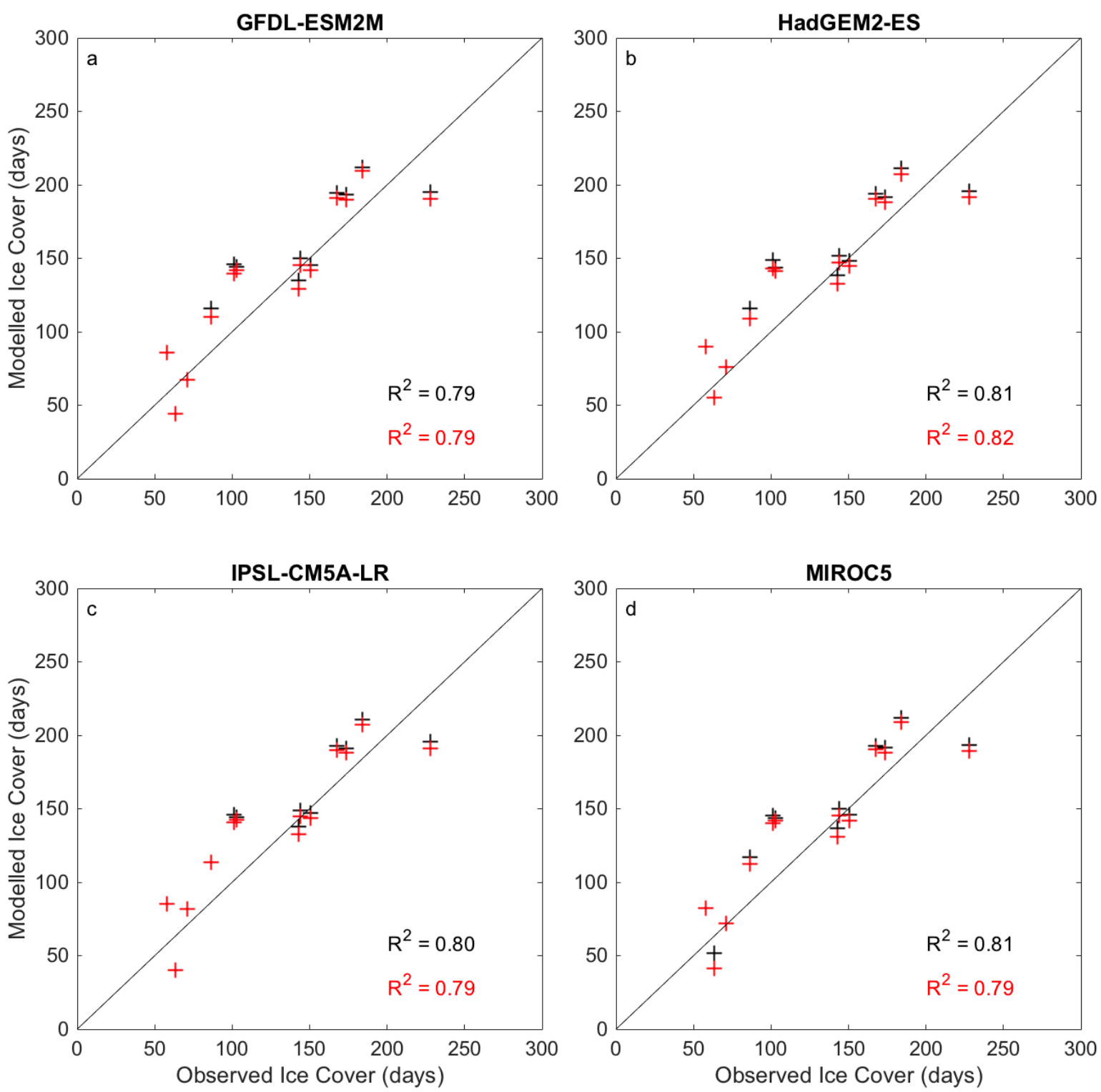

Figure S6. Comparison of modelled and observed (1995-2005) ice cover duration (in days) for lakes in which in-situ ice cover data were available and used in this study. The modelled lake temperatures represent those simulated by a lake model forced with bias-corrected climate projections available from the Inter-Sectoral Impact Model Intercomparison Project, namely (A) GFDL-ESM2M, (B) HadGEM2ES, (C) IPSL-CM5A-LR and (D) MIROC5. Time series data needed to drive the lake model from each climate projection were extracted for the grid point situated closest to the centre of each lake. To assess from the modelled lake surface temperatures the period during which a lake is likely ice covered, we (i) follow ref. 48 and characterise this as the period during which the lake-mean surface water temperature is $<1^{\circ} \mathrm{C}$ (black), and (ii) use the simulated period of non-zero ice thickness from the lake model (red). Observed ice cover data are from the Global Lake and River Ice Phenology Database ${ }^{62}$. Note that the average period of ice cover calculated for each lake will be based on a different time period, depending on the years in which observed ice cover data were available. Specifically, for some lakes only a few years of data are available, and thus the average observed ice cover duration will be different to that calculated using a 20 -year period (e.g., Fig. S5). 

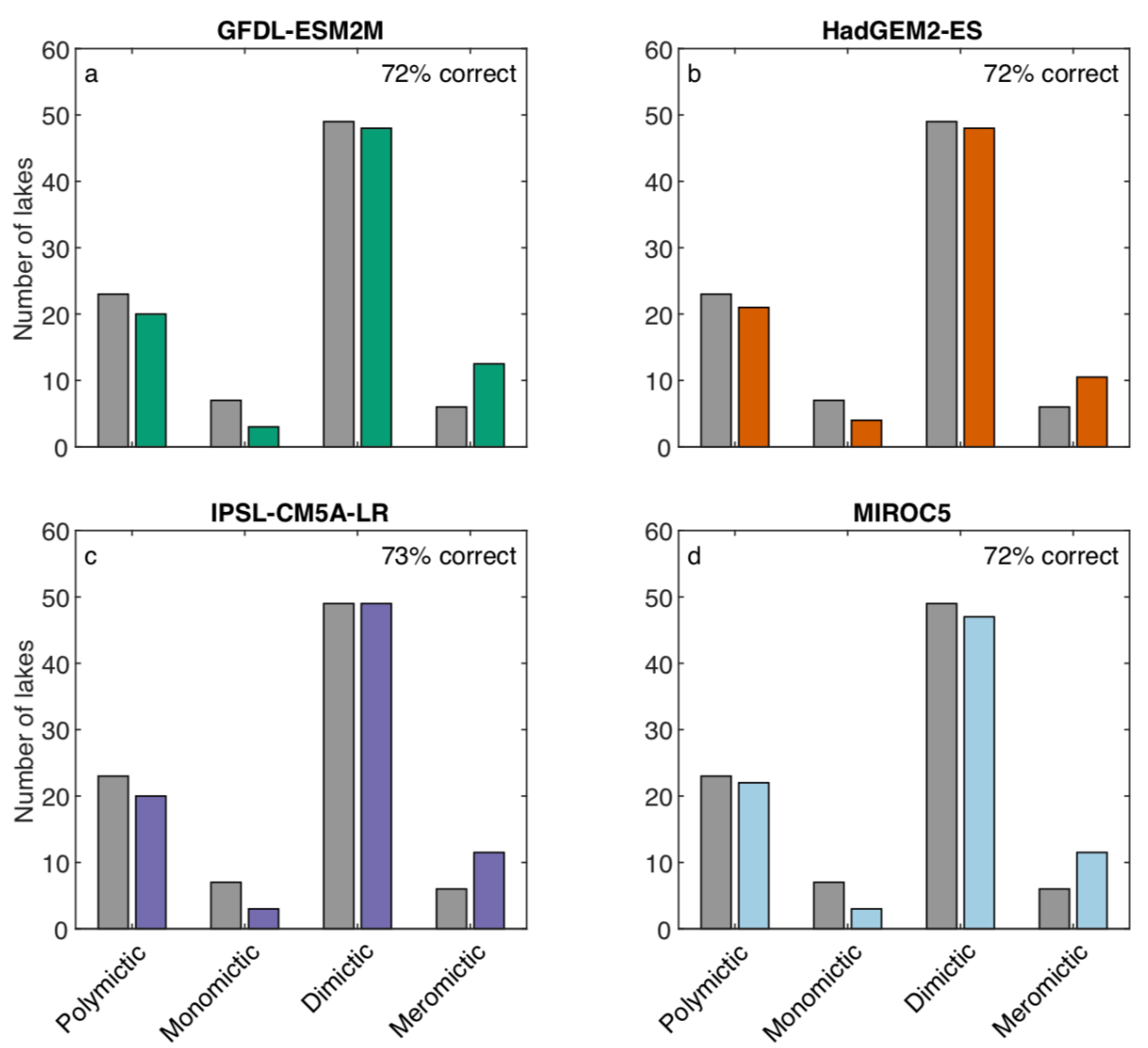

Figure S7. Comparison of modelled (grey) and literature defined (colour) mixing regimes of 85 lakes (Table S2). Modelled mixing regime classifications were defined following the method described in Fig. S1. Depth-resolved lake temperatures used in the lake mixing regime classification method were simulated by a lake model forced with bias-corrected climate projections available from the InterSectoral Impact Model Intercomparison Project, namely (A) GFDL-ESM2M, (B) HadGEM2-ES, (C) IPSL-CM5A-LR and (D) MIROC5. Time series data needed to drive the lake model from each climate projection were extracted for the grid point situated closest to the centre of each lake. For each climate model projection, we also show (see inset) the percentage of correctly defined mixing regimes by the lake model driven by each of the bias-corrected climate model projections. 

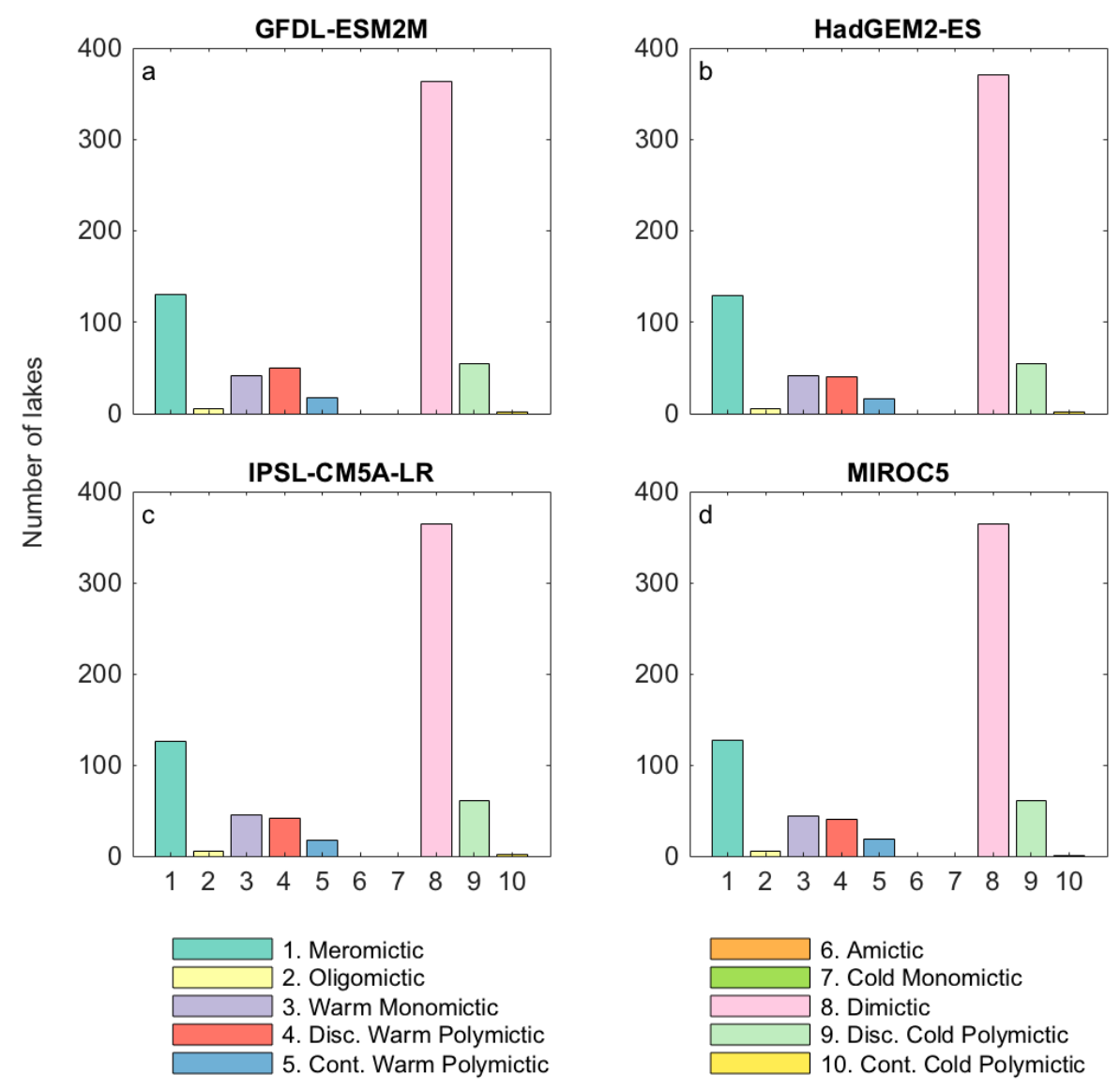

Figure S8. Comparison of modelled global lake mixing regimes identified using the classification scheme of ref. 16 and depth-resolved lake temperatures simulated by a lake model forced with biascorrected climate projections, namely (A) GFDL-ESM2M, (B) HadGEM2-ES, (C) IPSL-CM5A-LR and (D) MIROC5. 

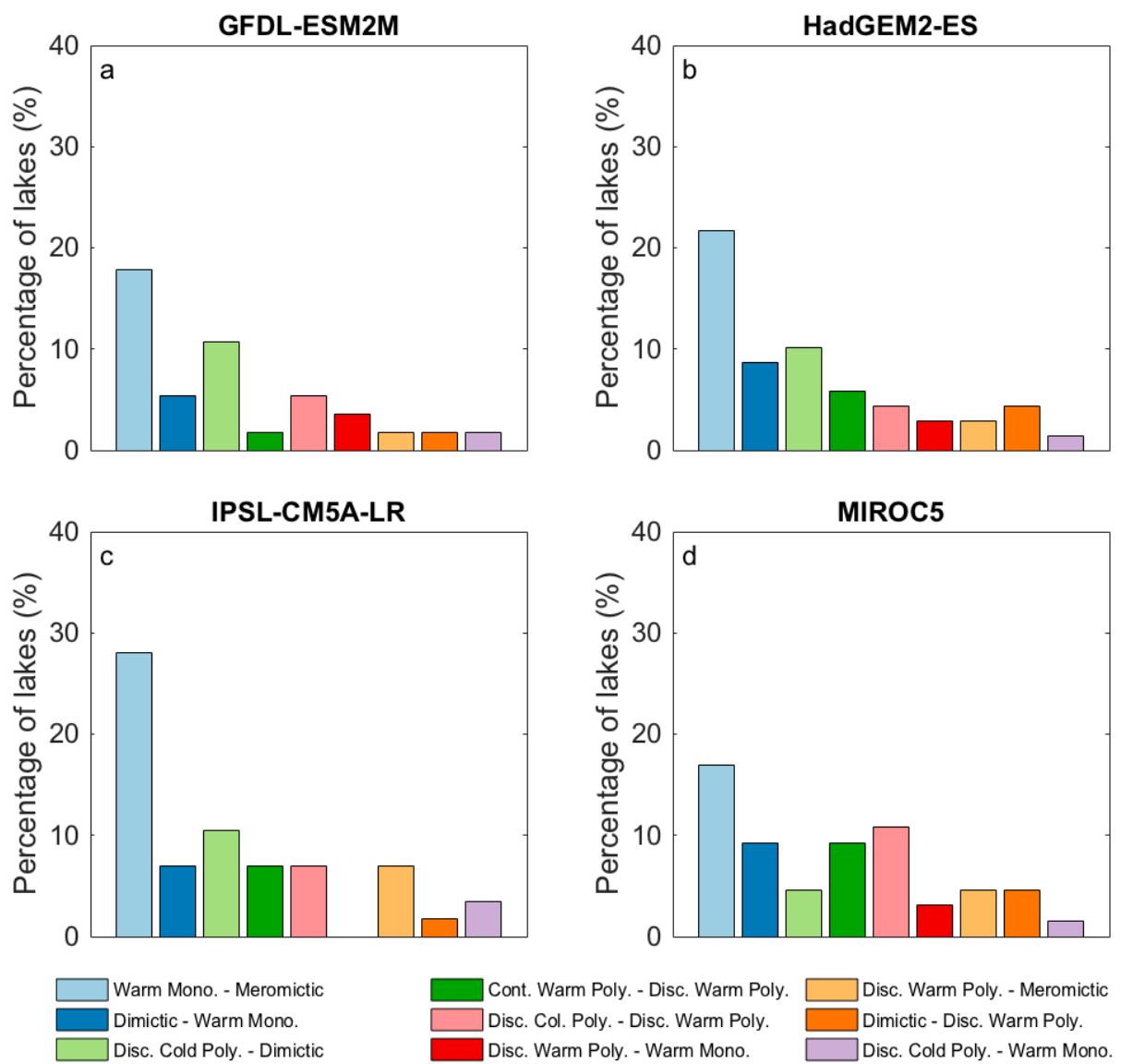

Figure S9. Comparison of climate-related changes in lake mixing regimes under RCP 2.6 using a lake model forced with bias-corrected climate projections, namely (A) GFDL-ESM2M, (B) HadGEM2-ES, (C) IPSL-CM5A-LR and (D) MIROC5. 

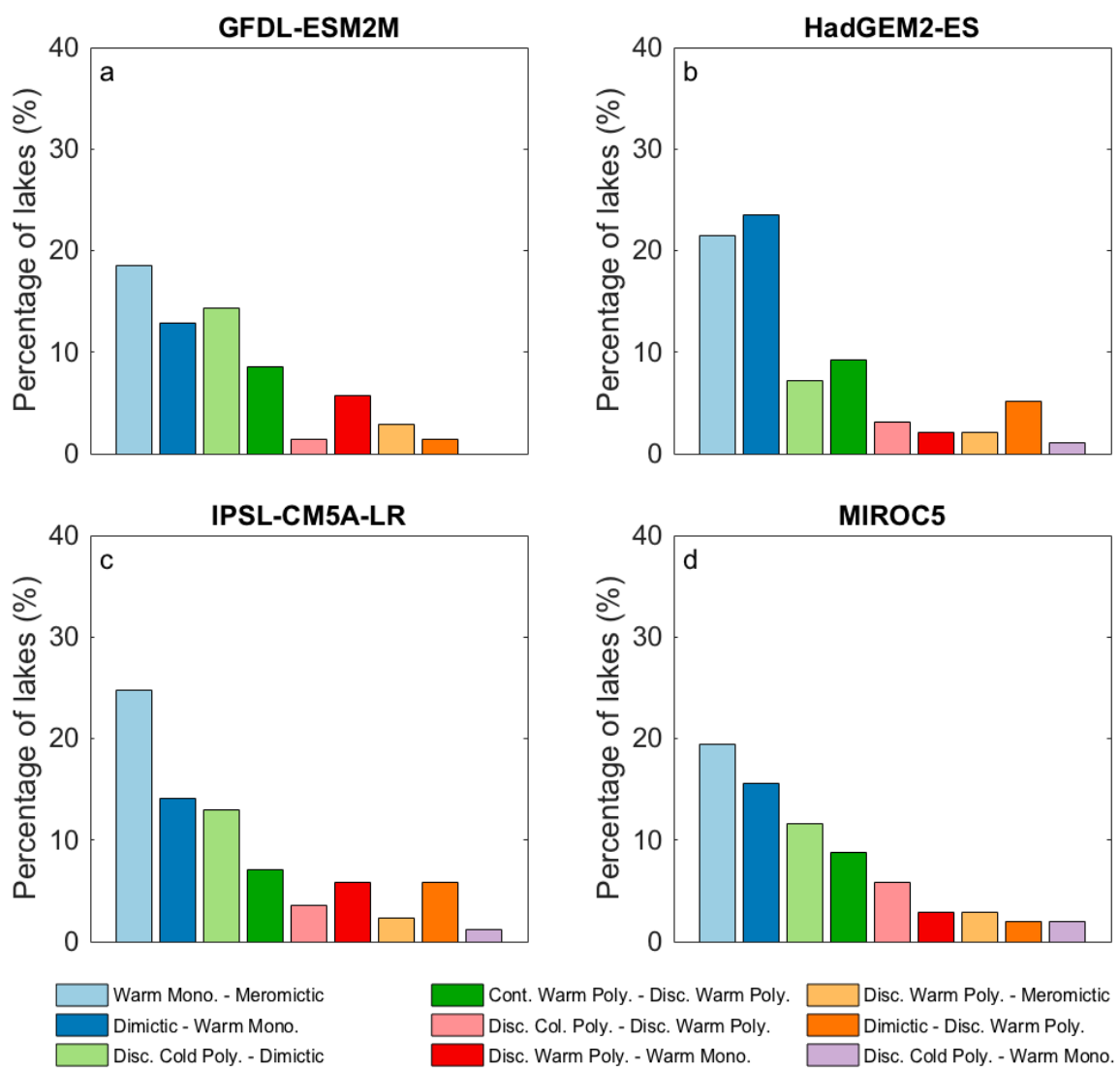

Figure S10. Comparison of climate-related changes in lake mixing regimes under RCP 6.0 using a lake model forced with bias-corrected climate projections, namely (A) GFDL-ESM2M, (B) HadGEM2-ES, (C) IPSL-CM5A-LR and (D) MIROC5. 